\title{
Article \\ Research on Trading Optimization Model of Virtual Power Plant in Medium- and Long-Term Market
}

\author{
Yungao Wu ${ }^{1,2}$, Jing Wu ${ }^{1, *}$ and Gejirifu De ${ }^{3}$ \\ 1 School of Economics and Management, North China Electric Power University, Beijing 102206, China; \\ wyg_2018@oit.edu.cn \\ 2 Department of Mathematics and Computer Engineering, Ordos Institute of Technology, Ordos 017000, China \\ 3 School of Electrical and Electronic Engineering, North China Electric Power University, Beijing 102206, China; \\ dove@ncepu.edu.cn \\ * Correspondence: wujingbj2018@sina.com
}

Citation: Wu, Y.; Wu, J.; De, G. Research on Trading Optimization Model of Virtual Power Plant in Medium- and Long-Term Market. Energies 2022, 15, 759. https:// doi.org/10.3390/en15030759

Academic Editors: Surender Reddy Salkuti and Anastasios Dounis

Received: 7 December 2021

Accepted: 15 January 2022

Published: 20 January 2022

Publisher's Note: MDPI stays neutral with regard to jurisdictional claims in published maps and institutional affiliations.

Copyright: (C) 2022 by the authors. Licensee MDPI, Basel, Switzerland. This article is an open access article distributed under the terms and conditions of the Creative Commons Attribution (CC BY) license (https:// creativecommons.org/licenses/by/ $4.0 /)$.

\begin{abstract}
In the medium- and long-term market, the power generation side and the power purchase side ensure to avoid the fluctuation of delivery prices through the medium- and long-term power contract, to avoid some market risks. This paper combines virtual power plants to aggregate distributed renewable energy to participate in market transactions. Firstly, this paper analyzes the two operation modes of power markets and combs the transaction varieties and modes in the mediumand long-term market. Secondly, the common contract power decomposition methods in the mediumand long-term market are analyzed, and the revenue model of virtual power plants is established. Then, combined with the renewable energy quota system and the green certificate trading mechanism, this paper constructs an optimization model of medium- and long-term contract trading of virtual power plants considering renewable energy derivatives. Finally, different renewable energy output scenarios are designed to analyze the benefits of virtual power plants in centralized and decentralized power markets. The example analysis shows the effectiveness of price difference contract for virtual power plants to ensure the renewable power revenue, which provides a certain reference for virtual power plants to participate in the power market.
\end{abstract}

Keywords: virtual power plant; medium- and long-term power market; contract for difference

\section{Introduction}

In 2015, China began a new round of power system reform and gradually built a multilevel market system. In order to fully tap the vitality of the power market and establish an orderly market mechanism, the medium- and long-term market is taken as a starting point. Recently, a market mechanism dominated by medium- and long-term transactions and supplemented by spot transactions is applied in many provinces and regions. The construction of the power market should pay equal attention to the utilization of renewable energy, expanding the utilization efficiency of renewable energy and diversifying its consumption path. By flexibly aggregating multiple types of energy units, virtual power plants (VPP) can participate in power market transactions, further enrich the diversification of the market, and improve the utilization efficiency of renewable energy.

Compared with mature power markets, China's power market reform was relatively late. In the future, it would continue to maintain the trading mode dominated by the medium- and long-term trading and gradually explore the spot market [1]. The main transaction types in the medium- and long-term market include bilateral negotiation contract transaction, monthly centralized competition transaction, and listing transaction [2-4]. For the power generators, the contract transaction can provide a certain guarantee for the stable benefits by locking the transaction power.

The connection between medium- and long-term and short-term markets lies on the contract power decomposition. Based on the construction of China's power market, 
literature [5] divided the construction of the spot market into three stages and put forward a medium- and long-term contract decomposition algorithm based on the financial delivery curve. Considering the unit maintenance periods, Literature [6] proposed a contract power decomposition method considering higher grid-connection of clean energy. Based on the construction of power market in Yunnan-Guizhou and the principles of system economy and fair distribution, Literature [7] proposed the optimal decomposition model of medium- and long-term contract power. Based on the participation of power producers and large users in the power spot market, Literature [8] proposed a price difference contract decomposition model based on social welfare maximization, which provides a reference for power producers to declare price difference contracts.

With the deepening of market reform and the continuous enrichment of the participants, renewable energy, such as wind power and solar power, gradually began to participate in market transactions [9]. The renewable energy transactions mainly include direct transaction with large users, regional delivery transaction, wind-thermal power replacement, heating transaction driven by wind power, spot transaction, and other transactions, which would effectively promote the consumption of renewable energy. However, due to the capacity limit and uncertain output, distributed wind power and photovoltaic $(\mathrm{PV})$ is not permitted to enter the market transaction currently. Therefore, distributed wind power, $\mathrm{PV}$, energy storage (ES), electric vehicles (EV), and other elements are combined, forming a united market participator. Literature [10] constructs a transaction optimization model to realize full consumption of clean energy combined with the monthly bidding trading rules in the medium- and long-term market and the auxiliary services provided by thermal power units to ensure the system operation stability. Literature [11] aggregates distributed resources to VPP and analyzes the optimization idea in market transactions. In Literature [12], VPP is regarded as a new concept which aggregates the capacities of various distributed energy resources and participates in the day-ahead market. The optimal scheduling of generation in VPP for the day-ahead market framework is studied.

There are some research directions on the path of renewable energy participating in market transactions now, but less analysis on distributed energy participating in the medium and long-term transaction. Most of the present research focused on the contract decomposition and power forecasting of the market or the renewable power output. Fewer studies performed relevant operation optimization for VPPs or other new-type market participators. Therefore, this paper analyzes the medium- and long-term power market and related operation characteristics in detail. Combined with the VPP aggregate of distributed resources, the contract transaction model considering two kinds of transaction modes is proposed, and the transaction optimization decision of VPP in the medium- and long-term contract market is further proposed. Thus, the operation strategy of VPP participating in the medium- and long-term power market can be provided for decision makers.

The paper is arranged as follows. Section 1 is the introduction, including the background of the paper and literature review. Section 2 introduces the structure of VPP and China's medium- and long-term power market. Section 3 proposed the idea of VPP participating in the medium- and long-term power market, analyzing the power decomposition method and the revenue of VPP from market transaction. By considering the renewable power quota system and green certificates, an optimal transaction model of VPP is established in Section 4. Section 5 contains the case study to verify the proposed model.

\section{Virtual Power Plant and China's Medium- and Long-Term Power Market}

\subsection{Power Market Modes}

Presently, combined with the market structure and trading products in various countries, the market operation mainly includes two modes: decentralized power market and centralized power market. The decentralized power market is mainly based on the mediumand long-term physical contract-that is, the power physics contract [13]. The amount of contract power can be independently decomposed into daily power amount by the buyers and sellers willingly, and the actual operation deviation power is adjusted through the day- 
ahead and real-time balance transaction. In the centralized power market, the spot trading is the main trading mode, and the centralized bidding is conducted for full power. As a means of financial settlement, the price difference contracts can help market participants avoid certain market risks to reach the optimal allocation of the market resources.

\subsubsection{Centralized Power Market}

The typical centralized power markets usually have the united dispatching and trading institutions, such as the PJM power market and the Australian power market, in which the real-time deviation is adjusted in spot market. Among them, the price difference contracts are widely used in the medium- and long-term market as the basis for settlement and have no impact on physical power system operation. According to the regulation scale, the spot market is divided into day-ahead, day-in, and real-time markets. The real-time bidding takes 5-15 min as a cycle. The bidding mode is full-power bidding. Due to the composition of the spot market, the centralized power market has the characteristics of high efficiency and flexible mobilization, but the supervision is difficult and the risk of price fluctuation is large. Therefore, it is more necessary for the financial market to avoid the corresponding risks.

\subsubsection{Decentralized Power Market}

The decentralized power market is mainly applied in the UK and Nordic power markets. The rules are relatively simple and applicable and can be managed in combination with regional characteristics. In the decentralized power market, the medium- and long-term market takes a large percentage, and the market operation can be ensured by fixing most of the electricity power. In addition, the participators in the decentralized power market can make independent selections of transaction categories according to their own demand, which also reflects the market transaction freedom, enlarging the decisive role of the market in resource allocation. Compared with the centralized power market, the decentralized power market allows the participators themselves to decompose the medium- and long-term power contracts, which includes a large amount of information, and has requirements for the power supply structure of the power grid.

\subsection{Structure of Virtual Power Plant}

VPP is the integration of power sources in a certain area, such as wind, PV, thermal, hydro, gas, and other resources, forming a unified virtual control center to dispatch a variety of power sources [14]. In a broader sense, the load side and the power side can be integrated by introducing demand response, energy storage, electric vehicles, etc., to realize the flexible source-load linkage and realize the orderly access of distributed energy power. In addition, the aggregation of distributed energy through VPP also provides a premise to participate in power market transactions.

As shown in Figure 1, the VPP is usually composed of distributed renewable energy generators (DREG), distributed fuel generators, energy storage system (ESS), controllable loads, etc. In addition, the coordinated operation of multiple components can be realized with demand response. The internal components of VPP can be divided into the following categories:

(1) Distributed renewable energy generators

DREGs include wind turbines, PV, etc. The output of DREG is greatly affected by weather and time, and the output has randomness and fluctuation. Therefore, there are certain risks and power losses during grid-connection. In order to suppress the power output uncertainty, management in advance is necessary - that is, through precise forecasting method and scenario method to eliminate the real-time deviation. Certain standby capacity and ESS are also needed. 
(2) Distributed fuel generators

Distributed fuel units generally include micro turbine (MT), micro combined heat and power unit (MT-CHP), biomass energy, etc. The output of distributed fuel units is stable. MTs and MT-CHPs can respond to the dispatching instructions of VPP quickly and adjust the output uncertainty caused by DREGs.

\section{(3) Energy storage system}

The ESS includes components with charging and discharging function, including energy storage devices, EV, and pumped storage power plants. Due to the flexible charging and discharging, ESS can purchase power to charge in the load valley period, and release power to sell in the load peak period to obtain profit through price difference. In addition, ESS can also be applied to standby regulation to translate the fluctuation of renewable energy output and grid-connection. ESS can also be combined with DREGs to recover excess power generation, in order to reduce the waste energy and improve the utilization efficiency of renewable energy.

(4) Demand response

Load variation has certain randomness for power system, and the load distribution has peak valley characteristics. As a controllable factor on the demand side, demand response (DR) can guide users to actively adjust load through price or relevant mechanisms, optimizing users' power consumption behavior, and form benign changes in load curve. DR can be divided into incentive demand response and price demand response. Price-based demand response (PBDR) stimulates users to adjust their power consumption behavior by giving price signals. Incentive-based demand response (IBDR) provides users with optional subsidy mechanism to encourage them to change power consumption behavior. Both PBDR and IBDR can be introduced in VPP to achieve a good interaction between the load side resources and the generation side.

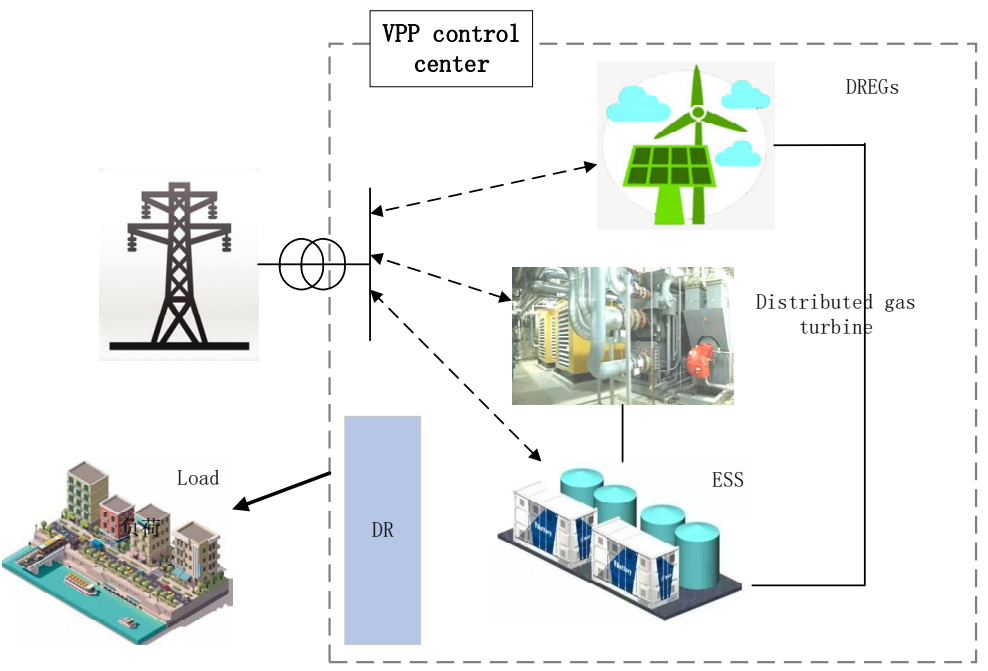

Figure 1. General structure of VPP.

\section{Optimization Analysis of Virtual Power Plant Participating in Medium- and} Long-Term Power Market Transaction

\subsection{Contract Transaction Mechanism in Medium- and Long-Term Market}

Since power cannot be easily stored as physical form, the medium- and long-term contract can be seen as a virtual inventory, which can provide some ex-protection to avoid the large price fluctuation in the power spot market. In other words, medium- and longterm contract transaction is not only a form of transaction, but also a means to prevent risks.

Two main forms of contracts are applied in the medium- and long-term electricity trading market: physical contract and contract for difference (CFD). Physical contract 
mainly refers to the contract signed by both parties to agree to deliver power trade in the future. The fixed contract stipulates the time, power quantity, and price of future transactions, and shall be executed according to the fixed mode of the contract. Physical contract has strong feasibility in the process of power marketization because of the clear rules and great flexibility.

In the future development of the power market, the spot market will become an important way to allocate market resources, and the clearing price will bring price fluctuation risk to the market participators. In order to avoid the price fluctuation risk from spot market, medium- and long-term power CFD is applied. The CFD is based on the agreed price reached by both parties, and the financial delivery is carried out instead of physical execution.

In CFD, the price in the spot market is the benchmark for settlement. When the clearing price in the spot market is lower than the settlement price of the contract, if it is cleared at the spot market price, the power purchaser obtains higher benefits than that of the power seller. In order to avoid risks based on the mechanism of CFD, the power purchaser returns the extra benefits to the power seller difference. On the contrary, the seller will return the extra price difference fee to power purchaser. CFD can settle in the spot market and does not require physical execution. Therefore, the settlement of CFD will not actively restrict the resource allocation of the market.

From the perspective of total contract amount, CFD can be divided into quantitative CFD and non-quantitative CFD. The uncertainty of the non-quantitative CFD comes from the uncertainty of user power consumption and the uncertainty of power generation. As China's power market has not been fully liberalized at present, part of users do not participate into market trading now, and their power consumption is still settled according to the catalog price, which can be regarded as a CFD of Power Grid Company providing a "last line" service. For the priority power generation in the market, the indemnificatory acquisition policy can be regarded as a price guarantee contract.

\subsection{Revenue Analysis of Virtual Power Plant in Medium- and Long-Term Market}

The VPP aggregates distributed resources and can ensure the consumption of renewable energy through the signing medium- and long-term market power contracts. In medium- and long-term power market transactions, fixed price contract and deviation assessment mechanism are the main factors affecting the medium- and long-term income of market participators.

\subsubsection{Contract Power Decomposition}

Due to the large time seesaw in the medium- and long-term power market, the VPP income in a specific time period is calculated based on power decomposition. The market participators decompose the contract power in combination with the historical load information. The "step-by-step decomposition" is usually used to decompose the annual power to months considering historical load curve and then to days and hours considering the load characteristics of weekends and working days and users' power consumption habits. The specific decomposition methods are shown in Figure 2.

(1) Daily average decomposition: take $15 \mathrm{~min}$ as a cycle, the daily power is decomposed into 96 time periods.

(2) Peak-period decomposition: the daily power is divided equally into the peak periods and the other time periods receive zero power decomposition.

(3) Normal-period decomposition: the daily power is divided into the normal periods, and the peak and valley periods receive zero power decomposition.

(4) Valley-period decomposition: the daily power is divided equally into the valley periods and the other time periods receive zero power decomposition.

(5) Peak-valley-normal period decomposition: the power distribution is set according to the peak-valley-normal periods. 


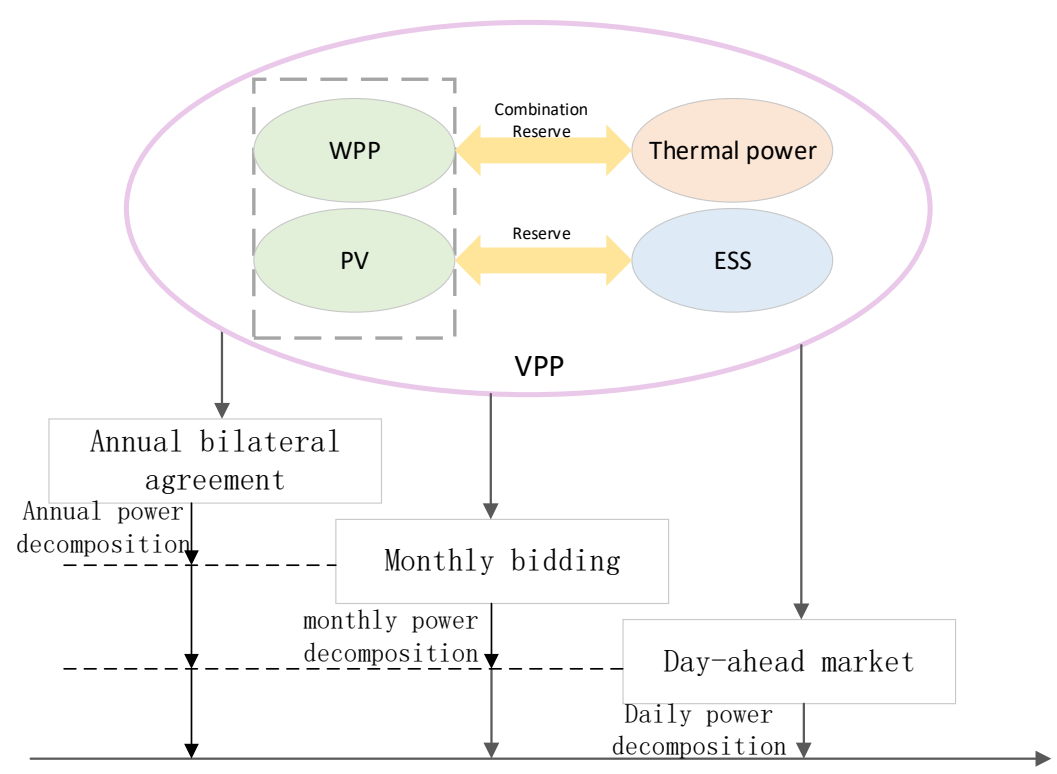

Figure 2. Decomposition form of medium-long term electricity of VPP.

\subsubsection{Deviation Assessment Cost}

Usually, the medium- and long-term contract power will be decomposed into daily curves, and the deviation appears between the real-time generation curve and the decomposition curve. The deviation shall be controlled within a certain range to avoid excessive economic punishment. The deviation assessment mechanism is generally settled on a monthly basis, and in order to avoid large penalties for VPP in the medium- and long-term market, the contract deviation coefficient $a_{\mathcal{C}}$ is usually introduced for power constraints, and $a_{c} \in[0,1]$

$$
\begin{gathered}
\left(1-a_{c}\right) P_{t}^{c} \leq P_{t}^{\text {real }} \leq\left(1+a_{c}\right) P_{t}^{c} \\
\sum_{t=1}^{T} P_{t}^{c}=\sum_{t=1}^{T} P_{t}^{\text {real }}
\end{gathered}
$$

wherein, $P_{t}^{c}$ is the contract power at time $t . P_{t}^{\text {real }}$ is the real-time power output of VPP at time $t$ within the contract power amount range.

For the power deviation, the punishment factor is specified.

$$
p_{\theta}=\left\{\begin{array}{l}
A p_{c}, \quad P_{t}^{\text {real }} \leq\left(1-a_{c}\right) P_{t}^{c} \\
B p_{c}, \quad P_{t}^{\text {real }} \geq\left(1+a_{c}\right) P_{t}^{c} \\
0, \quad\left(1-a_{c}\right) P_{t}^{c} \leq P_{t}^{\text {real }} \leq\left(1+a_{c}\right) P_{t}^{c}
\end{array}\right.
$$

wherein, $p_{\theta}$ is the punishing power price. $A$ and $B$ are the punishing coefficients of power negative deviation and positive deviation. $p_{c}$ is the average power price of generators.

\subsection{Revenue Analysis of Virtual Power Plant Considering CFD}

The capacity and power of distributed energy are small, thus it is not allowed in power market access. By flexibly aggregating multiple types of distributed power generation, VPP can improve the complementary utilization efficiency of distributed energy, and the aggregate can achieve the access conditions of the power market to obtain more economic benefits through market transactions. For the physical contract with fixed power settlement price, the CFD obviously has stronger risk aversion ability, and its financial settlement characteristics create greater profit space for VPP.

Generally, in the centralized power market mode, considering the strong output uncertainty of distributed energy and the price fluctuation in the spot market, VPP can avoid risks caused by CFD. The formula of CFD for VPP is as follows. 


$$
R_{c}=\left(p_{c}-p_{b}\right) Q_{c}
$$

wherein $p_{c}$ is the agreed price of CFD. $p_{b}$ is the benchmark price. $Q_{c}$ is the agreed power amount of CFD. $R_{c}$ is the avenue of VPP gaining from CFD.

Through CFD, the power generators can obtain the price difference compensation when the spot market price is low-that is, the price difference between the contract price $p_{\text {contract }}$ and the clearing price $p_{\text {spot }}$. If there is a regional power price where the generator is located, it can be compensated from the place with lower regional power price-that is, $p_{\text {spot }}-p_{\text {region }}$. The benefits of CFD obtained in the price area is $p_{\text {area }}$. Then, the revenue of power generators is as follows.

$$
\begin{aligned}
R_{\text {con }} & =Q\left[p_{\text {region }}+\left(p_{\text {contract }}-p_{\text {spot }}\right)+\left(p_{\text {spot }}-p_{\text {region }}\right)+p_{\text {area }}\right] \\
& =Q\left(p_{\text {contract }}+p_{\text {area }}\right)
\end{aligned}
$$

It can be seen that on considering CFD, the income of VPP is the fixed value without the impact of spot risk.

\section{Analysis of Medium- and Long-Term Contract Transaction of Virtual Power Plant Considering Renewable Energy Derivatives}

VPP aggregate distributed energy and participate in market transactions as a whole. In the market access rules, there is no open access policy for distributed PV and wind power. Thus, the distributed energy can combine micro-gas turbine and ESS to form a VPP, in order to create market competition opportunities. In addition, the generation costs of distributed wind power and PV are high and do not have advantages in market competition. Therefore, to further improve the competitive advantage of distributed energy, the renewable energy quota system and green certificate mechanism is introduced to reduce the competitive pressure of clean energy.

\subsection{Analysis on the Impact of Renewable Energy Quota System and Green Certificate Mechanism}

The development of renewable energy is an important means to solve the shortage of energy resources and environmental pollution [15]. If only the quota system is considered, the geographical distribution of distributed energy resources is ignored, resulting in the locality of resource allocation. As a supporting measure of the renewable energy quota system, the green certificate is sold through a unified online platform, which overcomes the regional restrictions on the consumption of renewable energy, realizes the cross regional allocation of renewable energy, and indirectly promotes the improvement of market efficiency [16]. Combined with the goal of the quota system, the subsidy cost of renewable energy is transformed into "commodity" in the form of transaction, promoting the development of renewable energy (please see Figure 3).

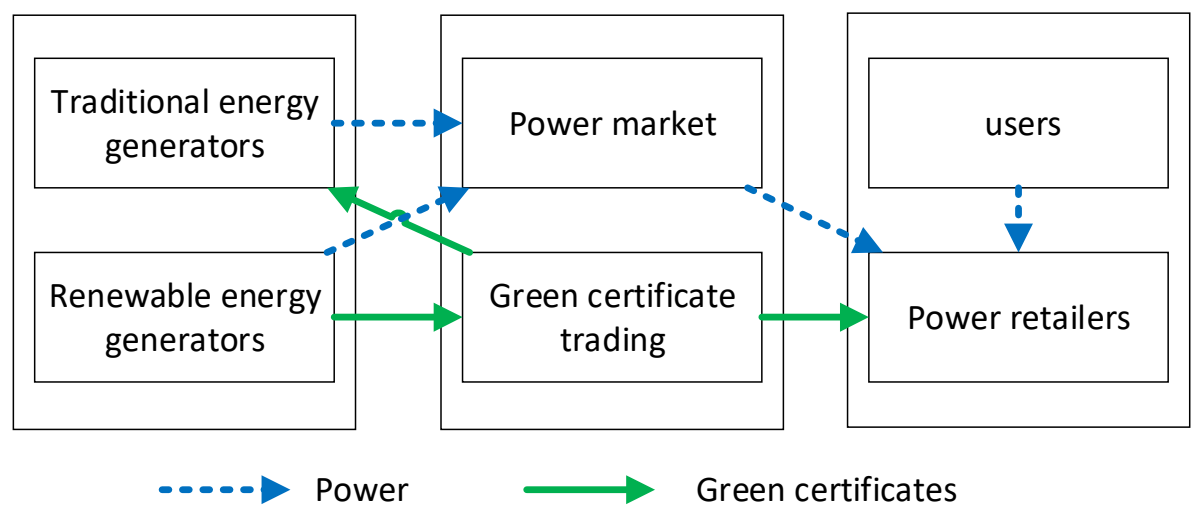

Figure 3. Power market and green certificate trading.

After the implementation of the quota system, in order to meet the requirements of the quota system, non-renewable energy enterprises can avoid the penalty cost caused by non-compliance by purchasing green certificates. Therefore, the profits of green certificate 
trading of renewable energy consist of two parts: one is the power price income obtained through trading, and the other is from the green certificate trading market.

In $V P P$, the distributed wind power and PV can reduce the power generation costs by selling green certificates, to build price advantage in medium- and long-term market transactions, as shown in Figure 3. Therefore, when VPP participating in the medium- and long-term market, the agreement price can be determined by green certificates.

$$
\begin{gathered}
p_{c o n}^{V P P}=p_{G}^{V P P}+p_{c o n}^{T P u} \\
p_{G} \leq \overline{p_{G}}
\end{gathered}
$$

wherein $p_{c o n}^{V P P}$ is the agreed price of $V P P^{\prime}$ s medium- and long-term contract. $p_{G}^{V P P}$ is the green certificate price of renewable generators in $V P P . \overline{p_{G}}$ is the average dealing price of green certificates. Formula (7) shows that, to ensure the trading scale of renewable energy, the price of green certificates can be lower to obtain more trading opportunities. After VPP signing the medium- and long-term transaction contract with users, the green power of $V P P$ transfers to the users and cannot be used in power market to obtain extra benefits.

\subsection{Medium- and Long-Term Contract Transaction of VPP Considering Renewable Energy Derivatives}

\subsubsection{Objective Function}

Considering the composition of VPP, the participation in the medium- and long-term power market is mainly reflected in two aspects. On one hand, market trading can improve the consumption of distributed wind power and PV. On the other hand, by promoting the consumption of distributed renewable energy, the combination with green certificate can bring more income. Ideally, the power output of the VPP is fully borne by the distributed wind power and PV units. At this time, the medium- and long-term market can help the $V P P$ realize the maximum output quantitative hedging. However, the output of distributed wind power and PV units is affected by weather and other reasons, coming with certain randomness and uncertainty, which requires assistance from distributed fuel units and controllable loads. Therefore, the goal of maximizing profits under the medium- and long-term market contract transaction of $V P P$ is shown as follows.

$$
\max \pi_{V P P}^{M L}=\sum_{t=1}^{N}\left(R_{V P P, t}^{M L}-C_{V P P, t}^{O p}\right)-p_{\theta} Q_{c o n}^{g a p}+n_{e x t r a, g} p_{G}^{V P P}
$$

wherein $R_{V P P}^{M L}$ is the income of $V P P$ participating in the medium- and long-term transaction market. $C_{V P P, t}^{O p}$ is the operation cost of $V P P$, containing the operation of $W P P, P V$, thermal units and ESS. $C_{V P P, t}^{\text {Gap }}$ is the deviation assessment costs of VPP at time $t . Q_{c o n}^{g a p}$ is the power deviation of $V P P$ between the contract decomposition and the real output. $n_{\text {extra, } g}$ represents the number of green certificates after removing the medium- and long-term contract power [17].

$$
N_{V P P}=\frac{Q_{P V}+Q_{W P P}}{1000(\mathrm{kWh})}
$$

wherein, $N_{V P P}$ is the total number of green certificates of $V P P$, which is calculated by the rule of $1 \mathrm{MWh}$ equaling one certificates.

$$
\begin{gathered}
N_{V P P}=\frac{Q_{P V}+Q_{W P P}}{1000(\mathrm{kWh})} \\
C_{V P P, t}^{O p}=\sum_{t=1}^{T} C_{t}^{W P P}+C_{t}^{P V}+C_{t}^{M T}+C_{t}^{E S S}+C_{G} \\
C_{G}= \begin{cases}0, & \frac{\left(Q_{W P P}+Q_{P V}\right)}{Q_{V P P}} \geq \eta \\
\frac{\left(Q_{M T}-Q_{W P P}-Q_{P V}\right)}{1000(\mathrm{kWh})} \cdot \overline{p_{G}}, & \frac{\left(Q_{W P P}+Q_{P V}\right)}{Q_{V P P}}<\eta\end{cases}
\end{gathered}
$$


wherein, $C_{t}^{W P P}, C_{t}^{P V}, C_{t}^{M T}, C_{t}^{E S S}$ are the operation cost of WPP, $P V$, micro-gas turbine (MT), and $E S S$ at time $t . C_{G}$ is the cost of green certificates of $V P P$, which is greater or equal than 0 . If $C_{G}>0$, it means that the VPP do not meet the renewable quota proportion and need to purchase certificates. $\eta$ represents the renewable energy quota proportion.

\subsubsection{Constraint Condition}

When participating in market transactions, $V P P$ should consider the stability of market operation and relevant constraints of market transactions, to ensure the stability of power system operation and the objectivity of market transactions. Therefore, relevant constraints include system operation balance constraints, power constraints, unit output characteristic constraints, reserve constraints, etc.

(1) System operation balance constraints

$$
Q_{V P P, t}^{D}+Q_{V P P, t}^{M L}=L_{t}
$$

wherein $L_{t}$ is the system load demand at time $t$.

(2) Medium- and long-term market contract transaction constraints

Considering that in the current reform of China's power market, the planning (power generation is planned annually) is parallel to the marketing. Here, studying the participation of VPP in the power market, only the marketing part is considered.

$$
\varphi Q_{\text {market }} \leq \sum_{t}^{N}\left[Q_{V P P, t}^{C f D}+Q_{V P P, t}^{J}\right] \leq Q_{\text {market }}
$$

wherein $\varphi$ is the minimum proportion of the medium- and long-term market power amount in the whole market. $Q_{\text {market }}$ is the marketing power amount, which is $(40 \%, 70 \%)$.

(3) WPP $, P V, E S S$ and $M T$ output constraints

$$
\begin{gathered}
Q_{W P P, t}^{D} \leq Q_{W P P, t} \\
Q_{P V, t}^{D} \leq Q_{P V, t} \\
u_{i, t} Q_{T i}^{\min } \leq Q_{T i, t}^{D} \leq u_{i, t} Q_{T i}^{\max } \\
u_{i, t} \Delta Q_{T i}^{-} \leq Q_{i, t}^{T}-Q_{i, t-1}^{T} \leq u_{i, t} \Delta Q_{T i}^{+} \\
\left(T_{T i, t-1}^{o n}-T_{T i, \min }^{o n}\right)\left(u_{i, t-1}-u_{i, t}\right) \leq 0 \\
\left(T_{T i, t-1}^{o f f}-T_{T i, \min }^{o f f}\right)\left(u_{i, t}-u_{i, t-1}\right) \leq 0 \\
0 \leq P_{\text {charge,t }}^{E S S} \leq \varphi_{E S S} P_{\text {charge,max }}^{E S S} \\
0 \leq P_{\text {discharge,t }}^{E S S} \leq \varphi_{E S S} P_{\text {discharge,max }}^{E S S}
\end{gathered}
$$

wherein $Q_{W P P, t}$ is the wind power generation amount. $Q_{T i}^{\max }$ and $Q_{T i}^{\min }$ are the output upper limit and lower limit of $M T^{i} . u_{i, t}$ represents the operation states of $M T$ and is a $0-1$ variation. 0 means that $M T$ is not started and 1 means that $M T$ is started. Equation (17) represents the climbing constraints of $M T$ units, $\Delta Q_{T i}^{-}$and $\Delta Q_{T i}^{+}$are the climbing upper limit and lower limit of $M T^{i} . T_{T i, t-1}^{o n}$ and $T_{T i, t-1}^{o f f}$ are the operation time length of $M T^{i}$ at time $t-1$. $T_{T i, \min }^{o n}$ and $T_{T i, \min }^{o f f}$ are the minimum time length of starting-up and shutting-down of $M T^{i} . P_{\text {charge, } \max }^{E S S}$ and $P_{\text {discharge, max }}^{E E S}$ are the maximum charging and discharging power of $E S S . \varphi_{E S S}$ represents the charging or discharging state of the ESS, and the charging and discharging state of the ESS cannot be at the same time. 
(4) Reserve constraints

$$
\begin{gathered}
\sum_{i=1}^{N} u_{i, t}\left(Q_{T i, t}^{\max }-Q_{T i, t}^{D}-Q_{T i, t}^{M L}\right) \geq R_{t}^{u p} \\
\sum_{i=1}^{N} u_{i, t}\left(Q_{T i, t}^{M L}+Q_{T i, t}^{D}-Q_{T i, t}^{\min }\right) \geq R_{t}^{\text {down }}
\end{gathered}
$$

wherein $R_{t}^{u p}$ is the upper reserve capacity of the system. $R_{t}^{\text {down }}$ is the lower reserve capacity of the system.

(5) Green certificate market constraint

$$
p_{G}^{V P P} \leq \overline{p_{G}} \leq p_{\text {punish }}
$$

wherein $p_{\text {punish }}$ is the punishing price when non-renewable generators fail to reach the quota standard.

\section{Case Study}

\subsection{Basic Data}

Taking a VPP with wind, PV, thermal, and power storage as an example, this paper studies its trading behavior in the medium- and long-term power market. In this case, the settlement cycle of the medium- and long-term market is 30 days, and the cycle of the green certificate trading market is 1 day. The daily load demand of the market is $4568 \mathrm{MWh}$, and the quota proportion of renewable energy is set as $13 \%$ with reference to the consumption proportion of each province specified in 2020 [18]. The average price of green certificate refers to the historical price of China's green certificate subscription trading platform from 2019 to the end of 2020. The average price is 172 yuan (26.96 USD)/piece, and the unit penalty is 360 yuan (56.43 USD)/ piece.

In this VPP of Western China, the power supply side includes $25 \mathrm{MW} \times 3$ wind turbine, $14 \mathrm{MW} \times 3 \mathrm{PV}$ power station, $40 \mathrm{MW}$ CHP unit, and $20 \mathrm{MW}$ energy storage device and the parameters of the generators are shown in Table 1 . The output parameters of the unit are shown in Table 1. Based on the historical generation output on certain typical days, 10 sets of forecasted power output of WPP and PV are simulated and take the average value of each time point as the final forecasted power [19]. The day-ahead market declaration curve of power purchasing enterprises and the average available power are shown in Figure 4.

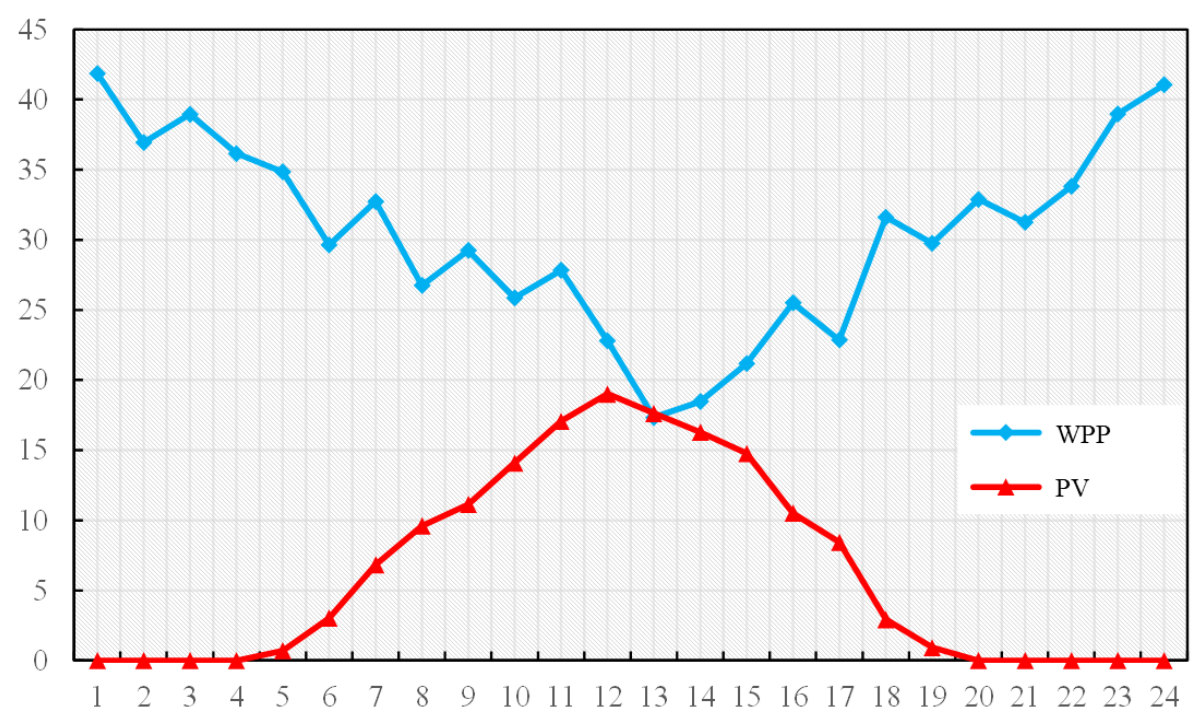

Figure 4. Available output power of wind and solar power (MWh). 
Table 1. Units' generation parameters setting.

\begin{tabular}{ccccccc}
\hline \multirow{2}{*}{ Units } & \multirow{2}{*}{$\begin{array}{c}\text { Maximum } \\
\text { Output (MW) }\end{array}$} & \multirow{2}{*}{$\begin{array}{c}\text { Minimum } \\
\text { Output (MW) }\end{array}$} & $\begin{array}{c}\text { Climbing } \\
\text { Speed (MW/h) }\end{array}$ & \multicolumn{3}{c}{ Unit Parameters } \\
\cline { 5 - 7 } MT & 40 & 6.5 & 1.5 & 0 & $\boldsymbol{b}$ & $\boldsymbol{c}$ \\
WPP & 25 & 0 & 8 & 0 & 0 & 0 \\
PV & 14 & 0 & 3.2 & 0 & 0 & 0 \\
\hline
\end{tabular}

In Table 2, the feed-in tariff of WPP is 296 yuan (47.03 USD)/MWh. The feed-in tariff of PV is 487 yuan (76.34 USD)/MWh. The penalty cost of curtailed wind power is 176 yuan (27.59 USD)/MWh, and the penalty cost of curtailed PV power is 243 yuan (38.09 USD)/MWh. The up-regulated standby quotation and down-regulated standby quotation are $150 / \mathrm{MWh}$ and $120 / \mathrm{MWh}$, respectively. The transaction price of thermal power bilateral agreement was 278.2 yuan (43.61 USD)/MWh. If the selling price of the green certificate of VPP is set at 164 yuan (25.71 USD)/piece, the transaction price of the annual bilateral contract is 442.2 yuan (69.32 USD)/MWh and the transaction power is $248.83 \mathrm{GWh}$. After annual and monthly power decomposition, the daily power is 691.2 MWh. Applying the peak-normal-valley decomposition rule, the daily contract power supply curve is as shown in Figure 5a (peak period: 9:00-15:00, 18:00-21:00; valley period: 23:00-7:00 the next day; normal period: 7:00-9:00, 15:00-18:00, 21:00-23:00). The deviation assessment coefficient is $3 \%$, and the penalty coefficient of the excess part is calculated as 1.2 times of the benchmark price of thermal units.

Table 2. Unit price setting of VPP (Yuan).

\begin{tabular}{cccc}
\hline Units & $\begin{array}{c}\text { Feed-In Tariff } \\
\text { (MWh) }\end{array}$ & $\begin{array}{c}\text { Contract Agreed } \\
\text { Price (MWh) }\end{array}$ & $\begin{array}{c}\text { Punishing Cost } \\
\text { (MWh) }\end{array}$ \\
\hline MT & 296 & 278.2 & - \\
WPP & 300 & 0 & 176 \\
PV & 487 & 0 & 243 \\
Green certificate & 176 & 164 & - \\
VPP & - & 442.2 & - \\
\hline
\end{tabular}

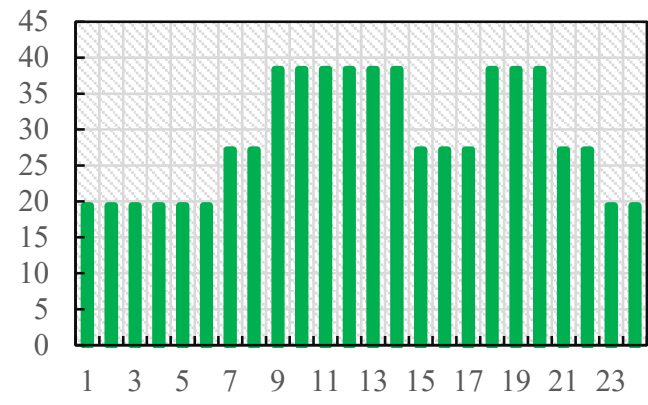

(a) Daily power decomposition of VPP (MWh)

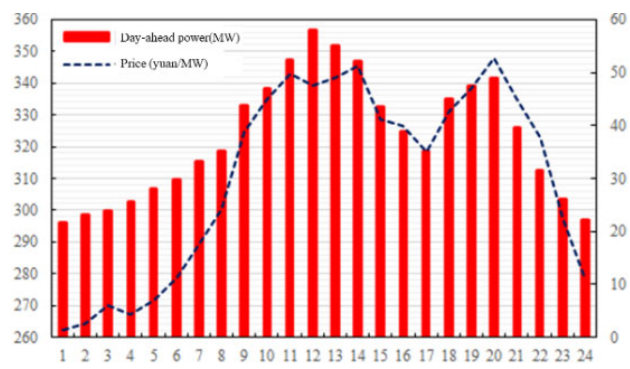

(b) Day-ahead market clearing

Figure 5. Daily electricity decomposition of VPP and market clearing.

\subsection{Scenarios Setting and Result Analysis}

If the DREGs generate power by the average level, the power output of VPP is shown in Figure 6.

It can be seen from Figure 6 that, based on the average output of all components, the VPP can meet the annual contract power signed. At the time, the economic benefits obtained by VPP signing fixed-price contracts for physical delivery under the decentralized power market mode are equal to those obtained from CFD under the centralized power market. However, in the actual operating process, the wind power output is strongly affected by weather, and the power output fluctuates greatly, which may lead to insufficient 
power supply to the contract power. In order to further study the income of the VPP under different contract modes, combined with the clearing price and power curve of the market in Figure 5b, three scenarios are designed to simulate the income of VPP participating in medium- and long-term contract trading under different market modes: normal output, insufficient output and no output of renewable energy.

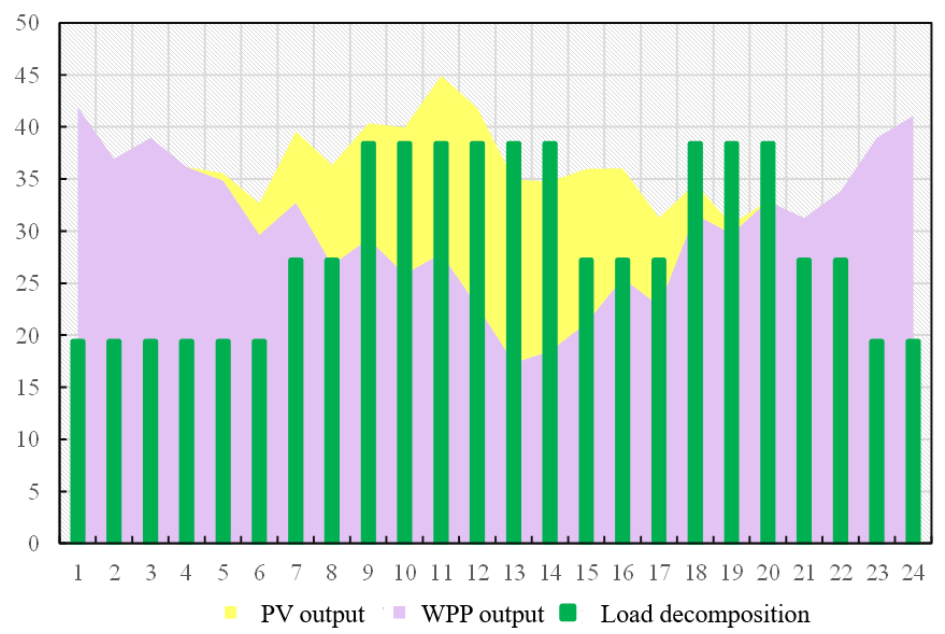

Figure 6. Average output of renewable energy in VPP (MWh).

(1) Normal output scenario

In normal output scenario, based on Figure 6, the daily output of VPP can meet the contract decomposition power requirement, which means the contract power can be cleared through the signed price and power amount of the medium- and long-term contract. The daily declared power besides the contract can be provided by the excess renewable power and other types of units in each period. The VPP output in the normal output scenario is shown in Figure 7.

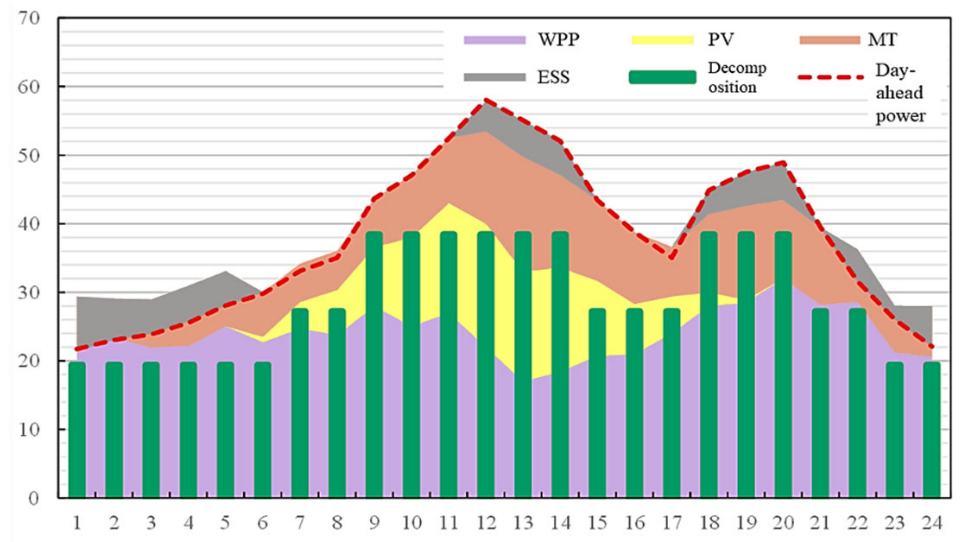

Figure 7. VPP output under conventional scenario (MWh).

In this scenario, if VPP settles according to the fixed-price contract, the total renewable power generation is $699.31 \mathrm{MWh}$, which can meet the daily contract-decomposition power. The output curve is obtained by combining the day-ahead market clearing curve and the objective function of participating in the medium- and long-term market, as shown in Figure 7. In the normal-output scenario, due to the "reverse" distribution of the wind power output and the load, the proportion of wind power output in valley periods is relatively higher, while less wind power proportion comes in the peak periods. Combined with the output of MT unit, the combination of ESS can realize the generation in time, to lead the output of VPP fitting the declared day-ahead curve. According to the VPP 
output, the strong output of WPP can be partially stored through ESS. And in the actual operation, the "power-heat" and "power-gas" conversion can also be realized through surplus wind power at night.

In this scenario, if the VPP carries out physical delivery, the contract income is 305,490 yuan. The total income of VPP is $374,669.7$ yuan $(58,731.78$ USD) and the net income is $190,706.7$ yuan $(29,894.14$ USD).

According to the normal output of renewable energy in VPP, in the centralized power market, the market adopts "full power competition", and CFD is applied to avoid the price risk of spot market. When the medium- and long-term contract price is higher than the day-ahead market clearing price, the number of medium- and long-term contracts has a positive effect on the income of VPP, and when the price fluctuates in the spot market, partial power benefits can be fixed to avoid the spot price risk.

(2) Insufficient output scenario

During the operation of VPP, part of distributed energy units may not start or generate in normal ways, resulting in a sharp reduction in the total output and not meeting the contract decomposition load of the day, as shown in Figure 8. MT and ESS in VPP need to be mobilized for assistance, then the benefits of VPP under CFD and fix-price contract varies.

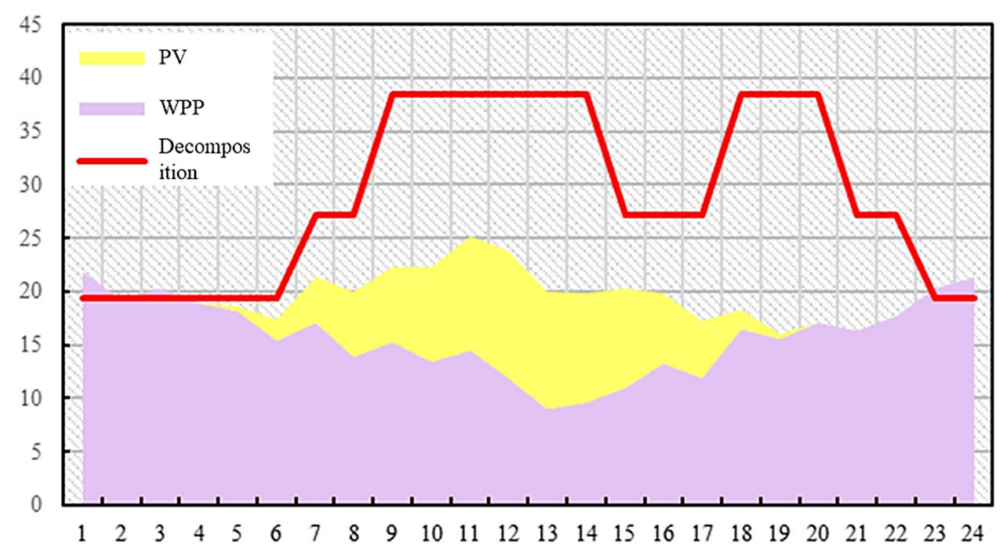

Figure 8. Contract power of VPP under insufficient output of renewable energy (MWh).

It can be seen from Figure 8 that the DREG output in VPP is poor, which is less than half of its average output level. Only the output of distributed wind and PV cannot meet the contracted daily power, thus VPP needs to mobilize other generator units for auxiliary output. In order to maximize the income of VPP, the output is shown in Figure 9.

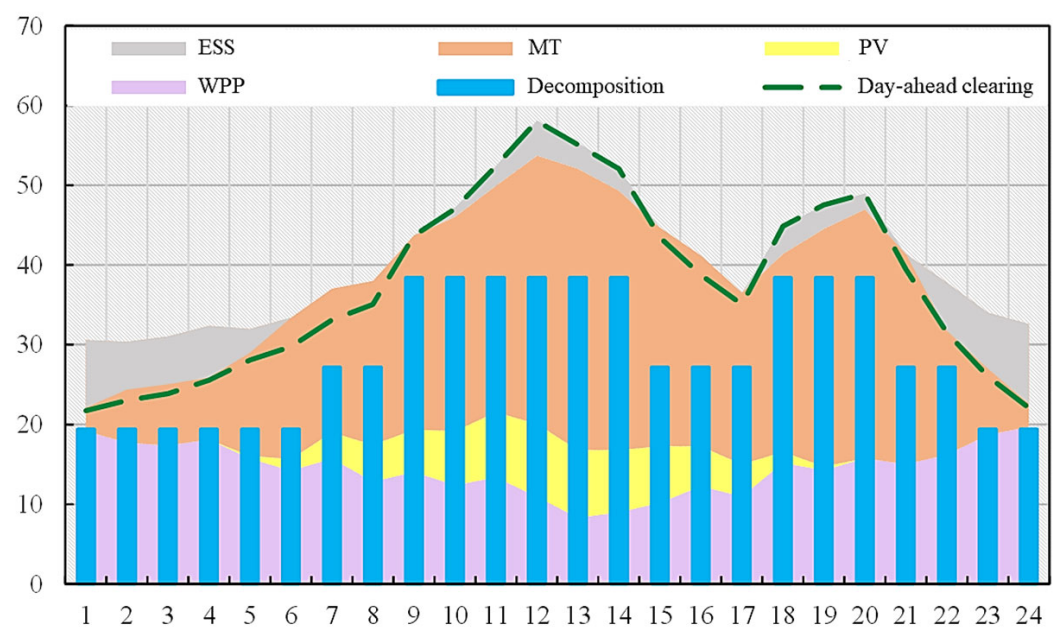

Figure 9. Power output of VPP under insufficient output of renewable energy (MWh). 
Under this scenario, if the fixed-price contract is implemented, the renewable energy power cannot meet the contracted decomposition power of the day, and there is a renewable power gap of $270.52 \mathrm{MWh}$. The VPP transfers other units, such as MT unit, and ESS to translate the generation power at the supply side to meet the day-ahead load curve. At 0:00-6:00 and after 21:00, ESS can charge with surplus wind power and discharge during the peak periods, which reduces the output burden of the conventional unit and improves the utilization efficiency of renewable energy. Under this scenario, VPP can meet the daily decomposition power of the contract by mobilizing units other than renewable power. However, the power used to meet the contract is not all renewable energy - that is, some power cannot provide corresponding green certificates, which should be supplemented by purchasing green certificates. The purchase cost of green certificates is 46,440 yuan. In this case, the green certificate purchase cost is even higher than the loss when bearing the deviation cost, thus the contract income of the VPP is further analyzed.

(1) In the decentralized power market, VPP adopts the "fixed-price contract" and "deviation assessment mechanism", and the physical delivery of contract power must be carried out. If only renewable electricity is used for settlement, there is a deviation of about $270 \mathrm{MWh}$. If the penalty cost is settled by the deviation assessment mechanism, the on-grid power price of coal-fired units is 284 yuan (44.52 USD)/MW, and the deviation assessment cost is about $85,125.26$ yuan (13,343.77 USD). The deviation assessment mechanism is usually settled monthly, and the change of total electricity in the cycle can be offset by the current electricity deviation, in order to reduce the average daily deviation assessment cost.

(2) In the centralized power market, VPP implements the price difference contract, which is only used for settlement and does not involve the actual power delivery. VPP obtains an income of 30,564,900 yuan (4,791,187 USD) through the CFD. The green certificate cost gap of VPP can be purchased through the green certificate market at a total cost of 46,440 yuan (7279.68 USD). In addition, if the guaranteed purchase policy of renewable energy is regarded as a kind of CFD with an agreed price, there is no need to consider the decomposition of contract power. Taking the actual power generation as the settlement volume, the contract revenue is 186,026 yuan $(29,160.42$ USD).

\section{(3) No output scenario}

During the operation of VPP, there is an extreme scenario of no output of renewable energy, and all the power decomposition of medium- and long-term contracts completely needs to be met by other units. By adjusting the operation of MT unit and ESS, the contract curve can be basically met. However, if participating in the day-ahead market, the output capacity of VPP will be limited to a certain extent. The operation state of VPP without renewable energy output is shown in Figure 10.

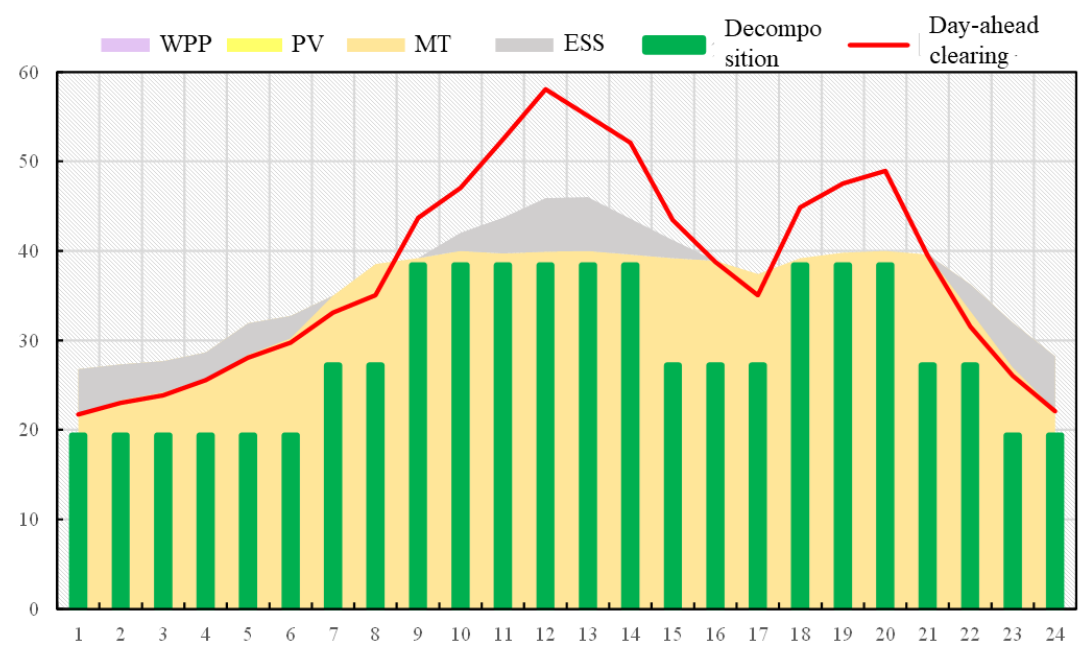

Figure 10. VPP operation status without renewable energy output (MWh). 
In this scenario, the renewable energy output is $0 \mathrm{MWh}$. The medium- and long-term transaction contract is met by MT units, but still, VPP cannot meet the forecasted day-ahead load curve. During the peak period (9:00-15:00, 18:00-20:00), there is an obvious power gap below the day-ahead curve, indicating that, in this case, VPP can only meet the decomposed power load of the medium- and long-term curve, and its participation in the day-ahead market is limited. At this time, all the green certificate transaction costs of VPP in the medium- and long-term contract signed need to be purchased from the green certificate market, and the green certificate cost to be borne is 118,886.4 yuan (18,635.98 USD). On this basis, the specific impact of VPP participating in the medium- and long-term contract signing mode is analyzed.

(1) In the decentralized power market, VPP adopts the "fixed-price contract" + deviation assessment mechanism and faces the physical delivery. If the assessment is based on the power generation capacity of CHP unit, the green certificate purchase fee of $118,886.4$ yuan is required, and the income from passing the contract is about 186,762.2 yuan $(29,275.89$ USD). If the contract is settled by renewable electricity, there is a contract electricity deviation of about 691.2 MWh. If the penalty cost is settled by the deviation assessment mechanism, the on-grid electricity price of coal-fired units is 284 yuan (44.52 USD)/MW, and the deviation assessment cost is 235,561 yuan (36,925.26 USD). In this scenario, the deviation assessment cost is high, and it is difficult to adjust through the power deviation in other directions in the monthly cycle. Therefore, if the renewable energy output is zero, VPP will face great risks if adopting the fixed-price contract in the medium- and long-term market.

(2) In the centralized power market, VPP implements the CFD, which is only used for settlement and does not involve the physical delivery. At this time, VPP locks an income of 30,564,900 yuan (4,791,187 USD) through CFD, but the supporting provision of green certificates needs considering. In addition, if the guaranteed purchase policy of renewable energy is regarded as a CFD at the agreed price, there is no need to consider the decomposition of contract power. Taking the actual power generation as the settlement volume, the corresponding default risk can be avoided.

From the analysis above, in extreme scenarios, VPP can also realize the protection of part of the income through CFD. For normal operation, the fixed-price contract can also ensure the renewable power generation benefits to a large extent, and the renewable energy quota system and the green certificate trading mechanism also provide better competitiveness for VPP with DREGs in market transactions. However, faced with great uncertainty of renewable energy output, CFD provides better guarantee for VPP based on its financial settlement characteristics, in order to improve the consumption level of renewable energy and promote the ability of market participation. However, there is an upper limit on the contract proportion in the centralized power market, which cannot completely avoid the risk.

\section{Conclusions}

Combined with the contract trading rules in the medium- and long-term market, this paper puts forward the income changes of VPP in the medium- and long-term market under different market modes. The transaction optimization model under the medium- and long-term market of VPP provides a certain reference for decision-makers. By introducing the renewable quota system and green certificate mechanism, the virtual battery will be competitive in the market. The case study shows that:

1. The fixed-price contract in the decentralized power market can provide effective economic guarantee for the VPP under the conventional output of renewable energy and considering deviations.

2. In extreme scenarios, CFD can help VPP avoid more risk losses in centralized power market, but it cannot completely avoid all price risks.

3. CFD will have better advantages in the development of spot market, especially for renewable energy aggregators. 
Based on this, this paper models and analyzes the revenue of VPP using CFD mode, but in the actual operation, the product types of medium- and long-term power market are richer, involving cross-provincial and cross-regional transaction forms, which has not been considered in this paper. The future work would take attentions on the regional power transaction, precisely, long-distance regional power transaction with more renewable power participating.

Author Contributions: Conceptualization, J.W. and Y.W.; methodology, J.W.; software, G.D.; validation, J.W., Y.W., and G.D.; formal analysis, Y.W.; investigation, Y.W.; resources, Y.W.; data curation, J.W.; writing—original draft preparation, J.W.; writing—review and editing, Y.W.; visualization, J.W.; supervision, Y.W.; project administration, G.D. All authors have read and agreed to the published version of the manuscript.

Funding: This research was funded by [Higher educational scientific research projects of Inner Mongolia Autonomous Region], grant number [NJZY22204].

Institutional Review Board Statement: Not applicable.

Informed Consent Statement: Not applicable.

Data Availability Statement: Not applicable.

Acknowledgments: All individuals have consented to the acknowledgement.

Conflicts of Interest: The authors declare no conflict of interest.

\section{References}

1. Ge, R.; Chen, L.; Wang, T.; Liu, D. Optimiazation and Design of Construction Route for Electricity Market in China. Automat. Electr. Power Syst. 2017, 41, 10-15.

2. Jin, L.; Chen, C.; Wang, X.; Yu, J.; Long, H. Research on information disclosure strategies of electricity retailers under new electricity reform in China. Sci. Total Environ. 2020, 710, 136382. [CrossRef] [PubMed]

3. Jo, S.H.; Woo, J.; Byun, G.S.; Jeong, J.-H.; Jeong, H. Study on the Integral Compensator Using Supercapacitor for Energy Harvesting in Low-Power Sections of Solar Energy. Energie 2021, 14, 2262. [CrossRef]

4. Zhao, F. Simulation and Implementation of Medium-And Long-Term Trading Algorithm in a Provincial Electricity Market. Master's Thesis, Dalian University of Technology, Dalian, China, 2019.

5. Guo, H.; Chen, Q.; Zhong, H.; Yang, W.; Zhang, W.; Xia, Q. Spot Market Mechanism Design and Path Planning Based on Standard Curve for Financial Delivery. Autom. Electr. Power Syst. 2017, 41, 1-8.

6. Zhao, S.; Hu, L.; Tian, J.; Xu, C. Contract Power Decomposition Model of Multi-energy Power System based on Mid-long Term Wind Power and Photovoltaic Forecasting. Electr. Power Autom. Equip. 2019, 39, 13-19.

7. Miao, S.; Luo, B.; Shen, J.; Cheng, C.; Li, G.; Sun, Y. Short-term Multi-objective Hydro-thermal Generation Dispatch considering Electricity Market Transition and Mid- and Long-term Contract Decomposition. Power Syst. Technol. 2018, 42, $2221-2231$.

8. Nie, Z.; Gao, F.; Wu, J.; Guan, X.; Liu, K. Contract for difference energy decomposition model for maximizing social benefit in electricity market. In Proceedings of the World Congresson Intelligent Controland Automation, Guilin, China, 12-15 June 2016; pp. 2449-2454.

9. Sun, L. Research on Optimal Dispatching of Virtual Power Plant under Electricity Market Environment. Master's Thesis, Dalian University of Technology, Dalian, China, 2020.

10. Wu, D.; Lu, J.; Li, G.; Yu, H.; Cheng, C. Compensation Method of Thermal Auxiliary Service under Electricity Market Environment with High Proportion of Clean Energy. South. Power Syst. Technol. 2018, 12, 78-85.

11. Zhang, G. Bidding Strategy and Coordinated Dispatch of Virtual Power Plant with Multiple Distributed Energy Resources. Ph.D. Thesis, Shanghai Jiao Tong University, Shanghai, China, 2019.

12. Pal, P.; Krishnamoorthy, P.A.; Rukmani, D.K.; Antony, S.J.; Ocheme, S.; Subramanian, C.; Elavarasan, R.M.; Das, N.; Hasanieri, H.N. Optimal Dispatch Strategy of Virtual Power Plant for Day-Ahead Market Framework. Appl. Sci. 2021, 11, 3814. [CrossRef]

13. Yu, X.; Li, G.; Cheng, C. Research and Application of Continuous Bidirectional Trading Mechanism in Yunnan Electricity Market. Energies 2019, 37, 4663. [CrossRef]

14. Wei, X.; Yang, D.; Ye, B. Operation Mode of Virtual Power Plant in Energy Internet and its Enlightenment. Electr. Power Construct. 2016, 37, 1-9.

15. Dong, F.; Ding, X.; Shi, L. Wind Power Pricing Game Strategy under the China's Market Trading Mechanism. Energies 2019, 12, 3456. [CrossRef]

16. Kildegaard, A. Green certificate markets, the risk of over-investment, and the role of long-term contracts. Energy Policy 2008, 36, 3413-3421. [CrossRef] 
17. Huang, Q. The Theoretical Analysis of Green Certificates Policy or Renewable Energy. J. Zhejiang Bus. Technol. Inst. 2011, 10, 34-39.

18. National Energy Administration. Notice on Establishing and Improving the Guarantee Mechanism for Renewable Energy Power Consumption; National Energy Administration: Beijing, China, 2019.

19. Shuai, D.; Wang, C.; Liang, J.; Dong, X.; Liang, H. Multi-objective Optimal Day-ahead Dispatch of Integrated Energy System Considering Power-to-gas Operation Cost. Automat. Electr. Power Syst. 2018, 42, 8-15. 